\title{
Overview of the Phytochemicals of Medicinal Plants to Lower Blood Pressure
}

\author{
Ike Novelia Affan ${ }^{1}$, Zikra Azizah $^{1}$, and Harrizul Rivai ${ }^{2 *}$
}

${ }^{1}$ College of Pharmacy (STIFARM), Jl. Raya Siteba Kurao Pagang, Padang 25147, Indonesia

${ }^{2}$ Faculty of Pharmacy, Andalas University, Limau Manih Campus, Padang 25163, Indonesia

DOI: $10.36347 /$ sajp.2020.v09i11.006

| Received: 15.11.2020 | Accepted: 26.11.2020 | Published: 29.11.2020

*Corresponding author: Harrizul Rivai

Abstract

This review article aims to find information about medicinal plants used to lower blood pressure (antihypertensives). The way to collect data is by using Google Scholar. The keywords used to find information were medicinal plants, antihypertensives, and phytochemicals. The results obtained from tracing information indicate that in the last 20 years of research, there were 21 medicinal plants used as antihypertensive drugs. These medicinal plants are garlic, celery, karira or kerda, chives, Terminalia arjuna, benalu, coconut trees, duck beak, new Chinese leaves, jeringau, prickly acacia, golden, silymarin, benalu parasites, king ulam, Marrubium vulgare, chickpea, nettle leaves, corydalis rhizome, fig, and joho rivet. These plants contain alkaloids, flavonoids, steroids, tannins, saponins, terpenoids, steroids. Plants that have antihypertensive properties contain the most flavonoids. We can be developed these plants into PhytoPharmaca for antihypertensive drugs.

Keywords: Phytochemicals, Antihypertensives, Hypotension, Medicinal Plants, Blood pressure.

Copyright $\odot$ ( 2020 The Author(s): This is an open-access article distributed under the terms of the Creative Commons Attribution 4.0 International License (CC BY-NC 4.0) which permits unrestricted use, distribution, and reproduction in any medium for non-commercial use provided the original author and source are credited.

\section{INTRODUCTION}

Hypertension or high blood pressure (BP) is a chronic medical condition and is a worldwide epidemic. A high percentage of the world's hypertensive population uses herbal medicines for primary health care because of their lower costs, better acceptance, and lower side effects. Natural medicinal plants, herbs with antihypertensive potential, so that several ethnobotany studies conducted in various parts of the world show that hundreds of plants are used worldwide to treat empiric hypertension. Basic knowledge of medicinal plants used to treat high blood pressure is needed to support future pharmacological and phytochemical investigations [1].

In the last three decades, a much-concerted effort has been put into researching local plants with hypotension and antihypertensives' therapeutic value. Some of these medicinal plants' hypotensive and antihypertensive effects have been validated, and others have not. However, traditional knowledge needs to be coupled with modern medicine. More scientific research needs to be done to verify their effectiveness and explain these herbal medicines' safety profile for their antihypertensive potential. Plants are a rich source of secondary metabolites which have been found to have antihypertensive properties in vivo. The current study is focused on examining the antihypertensive properties of medicinal plants and their metabolites. The use of natural compounds of plant origin as heartprotective agents and antihypertensives is an attractive strategy for finding bioactive products. Plants are rich in various secondary metabolites, such as flavonoids, alkaloids, tannins, and terpenoids. It has been found in vivo to have antihypertensive effects [2].

\section{DATA COLLECTION}

In the current review, we conducted a literature search using Google Scholar. The investigation included the keywords "herbs," "medicinal herbs," "plant extracts," cross-references to the keyword "hypertension," and "antihypertensive activity." In compiling this review article, the technique used is to use literature studies by finding sources or literature in primary data or the shape of official books and international journals in the last ten years (2010-2020).

\section{MEDICINAL PLANTS AS AN ANTIHYPERTENSION}

Twenty-one medicinal plants are used as antihypertensives. In the following, the medicinal plants 
will be described one by one, along with their chemical content, which may have antihypertensive properties.

\section{Garlic (Allium sativum L.)}

Garlic, which is used as an antihypertensive drug, is part of the tuber, as shown in Figure 1.

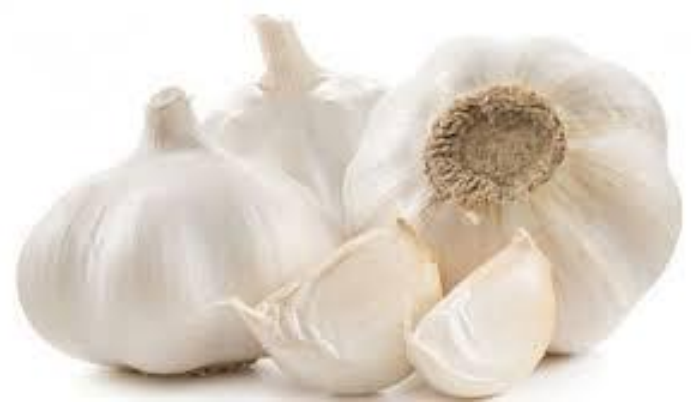

Fig-1: Garlic bulbs (Allium sativum L.)

There appears to be little literature on the toxicity of garlic widely used. Hence, it is important to investigate the chemical elements and chemical compounds present in garlic tubers and their safety for humans and consumers. Phytochemical screening and elemental analysis of Allium sativum L. tuber powder and its aqueous extract's toxicological effects were investigated in guinea pigs. Acute toxicity studies were carried out after subcutaneous administration of stratified doses of plant extracts in guinea pigs. The LD50 was $3034 \mathrm{mg} / \mathrm{kg}$, and the maximum tolerable dose was $2200 \mathrm{mg} / \mathrm{kg}$. The death occurred in rabbits given the extract of 3200 and $4200 \mathrm{mg} / \mathrm{kg}$ with other behavioral signs such as loss of appetite and partial paralysis. The percentage yield of extract was $75.8 \%$. Elemental analysis shows that the powdered plant material contains mainly potassium, phosphorus, and iron, among other elements. Meanwhile, phytochemical screening showed the following chemical compounds: saponins, steroids, tannins, carbohydrates, and cardiac glycosides, while alkaloids, cardenolides, flavonoids, anthraquinones, and cyanogenic glycosides were not found [3].

Allium sativum (garlic) was reported to act as an antihypertensive amid inconsistent evidence. This study investigated the cardiovascular effects of aqueous garlic extract (AGE) in normotensive and hypertensive mice using a two-kidney, one-clip (2K1C) model. Mean arterial blood pressure (MAP) and heart rate (HR) were measured in a normotensive and $2 \mathrm{~K} 1 \mathrm{C}$ mouse model anesthetized with thiopentone sodium $(50 \mathrm{mg} / \mathrm{kg}$ body weight i.p.) via the left common carotid artery connected to a recording device. The jugular vein is cannulated for drug administration. Intravenous injection of AGE $(5-20 \mathrm{mg} / \mathrm{kg})$ caused significant reductions ( $\mathrm{p}<0.05$ ) in MAP and HR in a dosedependent manner in both the normotension and $2 \mathrm{~K} 1 \mathrm{C}$ models, with more effect on normotension than in the 2K1C mouse model. The dose of $20 \mathrm{mg} / \mathrm{kg}$ AGE significantly $(\mathrm{p}<0.05)$ reduced systolic $(16.7 \pm 2.0 \%)$, diastolic $(26.7 \pm 5.2 \%)$, MAP $(23.1 \pm 3.6 \%)$ and HR $(38.4 \pm 4.3 \%)$ in normotensive rats. In the $2 \mathrm{~K} 1 \mathrm{C}$ group, significantly $(\mathrm{p}<0.05)$ decreased systolic $(22.2 \pm 2.1$ $\%)$, diastolic $(30.6 \pm 3.2 \%)$, MAP $(28.2 \pm 3.1 \%)$ and HR $(45.2 \pm 3.5 \%)$ of basal level. Pulse pressure increased significantly $(\mathrm{P}<0.05)(33.3 \pm 5.1 \%)$ in the $2 \mathrm{~K} 1 \mathrm{C}$ group. Initial treatment of animals with the muscarinic receptor antagonist, atropine $(2 \mathrm{mg} / \mathrm{kg}$, i.v. $)$, did not affect the extract's negative hypotensive and chronotropic activity. AGE induces decreased blood pressure and bradycardia by a direct mechanism that does not involve the cholinergic pathway in normotensive and 2K1C mice, suggesting the possible involvement of peripheral hypotension mechanisms [4].

\section{Celery (Apium graveolens L.)}

Celery (Apium graveolens L.), used as a medicinal plant for antihypertensives, is shown in Figure 2

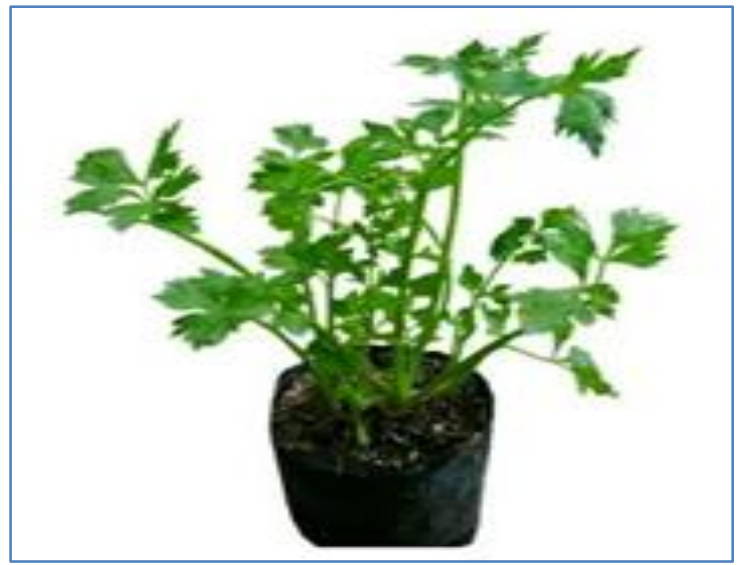

Fig-2: Celery (Apium graveolens L.)

Apium graveolens (celery plant) is a native plant belonging to the Apiaceae family. This herb has a broad spectrum for an aphrodisiac, anthelmintic, antispasmodic, carminative, diuretic, emmenagogue, laxative, sedative, stimulant poisonous. Celery is known to be a mild diuretic and urinary antiseptic and has relieved flatulence and bothersome pain. Literature data reveal that A. graveolens has many pharmacological properties such as antifungal, antihypertensive and hypolipidemic, diuretic, anticancer, and many more [5].

Essential oils, phenolic acids, and other constituents in three celery accessions (Apium graveolens L) were studied to determine the phytochemical variability that caused differences in yield and phytochemical profiles. Celery accessions are grown in pots under the same environmental conditions. The analysis was carried out on two crops with three harvests to determine and compare the levels of anthocyanins, carotenoids, chlorophyll, phenolic acid, rosmarinic acid, and dissolved sugar tannins, and the content of essential oils. Except for carotenoids, significant variations in phytochemical profiles among the three celery accessions were observed [6]. 


\section{Karira or kerda (Capparis decidua Forsk.)}

Karira or kerda (Capparis decidua Forsk) plants used as antihypertensive drugs are shown in Figure 3.

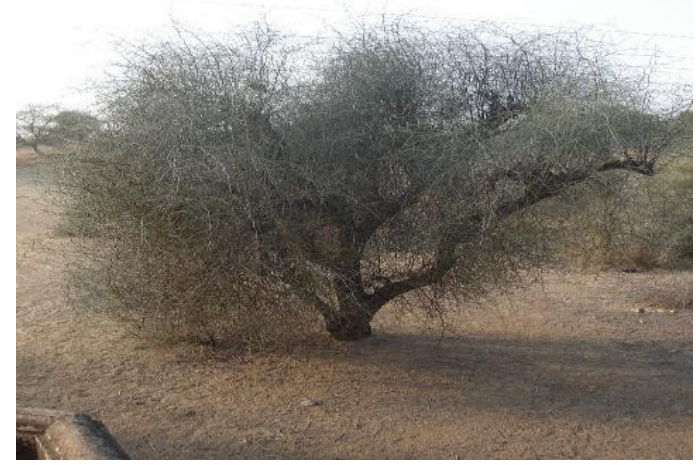

Fig-3: Karira or kerda (Capparis decidua Forsk.)

Capparis decidua Forsk belongs to the Capparidaceae family is an important medicinal plant of Indian medicinal plants. In the traditional Indian medicine system, the bark is useful in treating coughs, asthma, and inflammation. The root is used for fever, and the bud is used for the treatment of boils. In the Unani medicinal system, the leaves are used to help with heart problems. This herb contains alkaloids, terpenoids, glycosides, and several fatty acids [7].

The hypotensive activity of the ethanol extract of C. decidua at a dose of $1-30 \mathrm{mg} / \mathrm{kg}$ was given depending on the amount of blood pressure and heart rate in animal experiments. Whereas in guinea pigs, the extract caused atrial contraction depending on the concentration, decreased strength, and atrial contraction speed. However, the extract showed norepinephrine inhibition or potassium-induced contraction. Furthermore, the extract inhibited contraction at the submaximal level with $1 \mathrm{mg}$ of extract produced acetylcholine, histamine, and histidine. These manifest directly in $\mathrm{C}$. decidua extract's relaxing action on the myocardium and blood vessels that could be responsible for its hypotensive action [7].

\section{Leaves of chives (Allium schoenoprasum L.)}

The leaves of chives (Allium schoenoprasum L.), which are used as antihypertensive drugs, are shown in Figure 4.

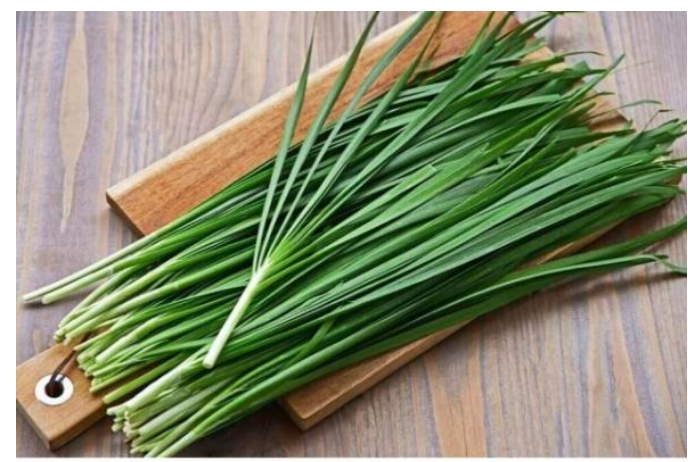

Fig-4: Leaves of chives (Allium schoenoprasum L.)
Allium schoenoprasum L. (family Amaryllidaceae), commonly known as chives, has a high culinary value besides being used as ethnomedicine. The phytochemical and pharmacological activities of A. schoenoprasum are discussed, and future opportunities for systematic investigation. The leaves' scientific evaluation validates its traditional claims and demonstrates a wide range of pharmacological potentials, including antiinflammatory, anticancer, antioxidant, anthelmintic, and antihypertensive. Although phytochemical studies reveal sulfur and phenolic compounds, flavonoids, saponins, and steroid glycosides, systematic research to identify bioactive compounds is needed. This review confirms the importance of A. schoenoprasum treatment. It could encourage future research on aspects of it that have not been explored, particularly the identification of bioactive compounds and their associated mechanisms and safety, which may be for their development as drugs [8].

\section{Arjuna (Terminalia arjuna Wight \& Arn.)}

The Terminalia arjuna tree used as an antihypertensive drug is shown in Figure 5 below.

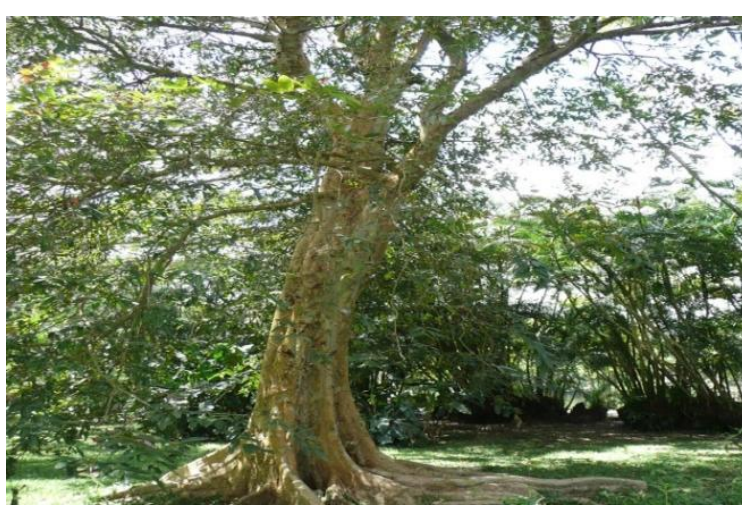

Fig-5: Terminalia arjuna Wight \& Arn tree

Terminalia arjuna Wight \& Arn (Combretaceae) is a tree that has broad medicinal potential. This plant is traditionally used in the treatment of various diseases. T. arjuna is an excellent hypocholesterolemic, hypolipidemic, anticoagulant, antihypertensive, antithrombotic, antiviral, antifungal antibacterial drug. Various parts of the plant have been investigated for the presence of phytoconstituents and their pharmacological activity. Many useful phytoconstituents have been isolated from $\mathrm{T}$. arjuna. Triterpenoids are mainly responsible for cardiovascular properties. Tannins and flavonoids are responsible for their anticancer properties [9].

\section{Benalu (Loranthus micranthus)}

Benalu (Loranthus micranthus), which is used as an antihypertensive, is shown in Figure 6 below. 


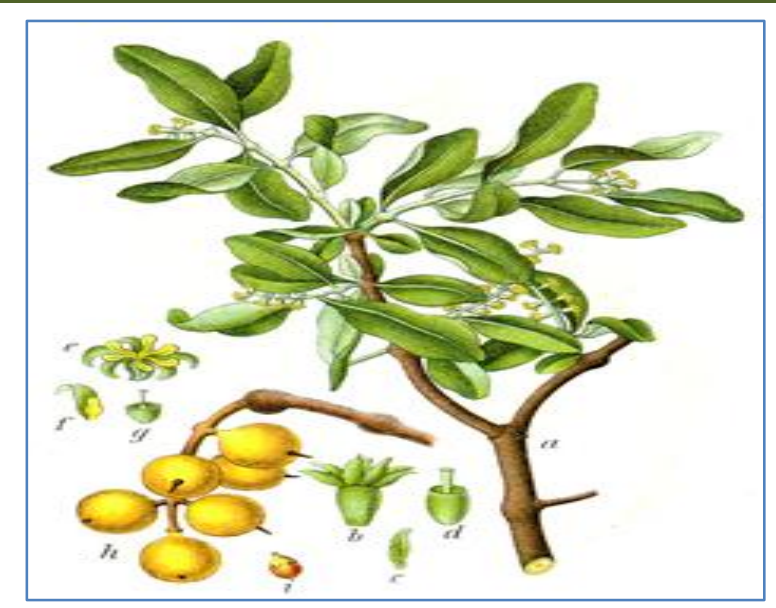

Fig-6: Benalu (Loranthus micranthus)

Loranthus micranthus Linn. is a medicinal plant from the Loranthaceae family, commonly known as the eastern Nigerian African mistletoe species. It is widely used in folkloric medicine to cure various ailments. This plant is semi-parasitic because it grows on multiple host trees and shrubs and absorbs mineral nutrients and water from their respective hosts. Therefore, the phytochemical and biological activities of L. micranthus show dependence on a healthy host and harvest period. The leaves are shown to have immunomodulatory, antidiabetic, antimicrobial, antihypertensive, antioxidant, antidiarrheal, and hypolipidemic activities [10].

Phytochemical analysis of Loranthus micranthus showed steroids, terpenoids, alkaloids, flavonoids, glycosides, carbohydrates, saponins, and acid compounds in crude extracts and carbohydrates, flavonoids, terpenoids, and oil in the weak acid fraction. Further purification of the soft acid fraction of the methanol extract using thin-layer chromatography showed that toluene: methanol: diethylamine (3: 1: 1) and chloroform: methanol: diethylamine (9: 1: 1) were the best solvent systems. These solvent systems were for the isolation of various components of the weak acid fraction of the methanolic extract of Loranthus micranthus [26].

Loranthus micranthus (LM), also called African mistletoe, is the main Nigerian Loranthaceae plant used traditionally to treat hypertension. Plant leaf methanol extract (LMME) has been shown to induce antihypertensive activity in mice, but the mechanism is still unclear. This research was conducted to study the effect of LM on the pressor-induced contraction of rats' aortic smooth muscle and serum lipid profiles in mice. LMME was partitioned to produce fractions of $\mathrm{n}$ butanol (NBF-LMME), chloroform (CF-LMME), ethyl acetate (EAF-LMME), and water (WF-LMME). The median effective concentration and maximum relaxation fraction were determined against epinephrine and a $\mathrm{KCl}$ pre-contracted rat aortic ring model. Serum lipid profiles and nitric oxide (NO) were determined spectrophotometrically in mice given orally $250 \mathrm{mg} / \mathrm{kg}$ b.w. each fraction for 21 days. Data were analyzed statistically. NBF-LMME exerted the highest dosedependent inhibitory effect in the aorta of mice previously contracted with norepinephrine and $\mathrm{KCl}$, followed by descending order by WF-LMME> CFLMME> EAF-LMME. A similar activity sequence was observed in this fraction's ability to inhibit elevated arteriogenic lipids, increase serum nitric oxide, and reduce cardiac arginase in mice. We concluded that the antihypertensive activity of L. micranthus involved anti-arteriogenic events, vasorelaxation, reduced cardiac arginase, and increased NO [27].

\section{Coconut Tree (Cocos nucifera L.)}

The coconut tree (Cocos nucifera L.), used as an antihypertensive drug, is shown in Figure 7 below.

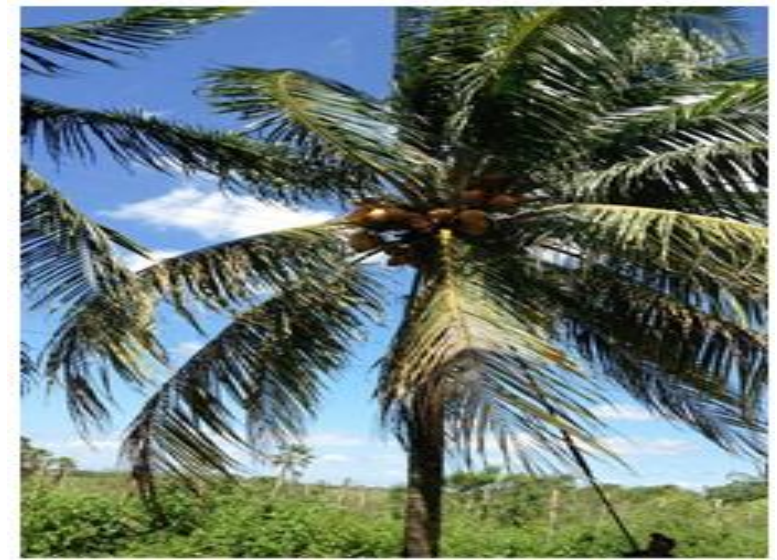

Fig-7: The coconut tree (Cocos nucifera L.)

Cocos nucifera (L.) (Arecaceae) is commonly called the "coconut tree" and is the most naturally distributed fruit crop on Earth. Throughout history, humans have used medicinal plants as therapy, and minerals, plants, and animals have traditionally been the primary sources of medicine. The content of C. nucifera has several biological effects, including antihelminthic, anti-inflammatory, antinociceptive, antioxidant, antifungal, antimicrobial, and antitumor activity. Some of the plant uses are partly confirmed by previous studies showing analgesic, antiarthritic, antibacterial, antipyretic, antihelminthic, antidiarrheal, and hypoglycemic activities. Other properties include antihypertensive, anti-inflammatory, antimicrobial, antioxidant, cardioprotective, antiseizure, cytotoxicity and hepatoprotective vasodilating, nephroprotective, and anti-osteoporotic effects were also reported. Because each part of $C$. nucifera has different constituents, its pharmacological effect varies according to the plant part being evaluated [11].

Fruit Cocos nucifera Linn. (Arecaceae) has long been used in traditional medicine to treat cardiovascular disorders. This study aimed to evaluate the ethanol extract of Cocos nucifera Linn. endocarp (CNE) for vasorelaxant activity in isolated rat aortic ring and antihypertensive effect hypertensive rats 
induced by deoxycorticosterone acetate (DOCA) salt. Endocarp Cocos nucifera Linn. extracted with ethanol and characterized by HPLC. CNE was examined for the effect of in vitro vascular relaxants on isolated norepinephrine, phenylephrine, or potassium chloride pre-contracting the aortic ring (both intact and denuded endothelium). An in vivo antihypertensive study was conducted on male Wistar rats that were not induced by DOCA salt and induced by salt. Endothelium removal or pre-treatment of the aortic ring (intact endothelium) with 1-NNA $(10 \mu \mathrm{M})$ or ODQ $(10 \mu \mathrm{M})$ followed by addition of a contractile agonist before CNE significantly blocked CNE-induced relaxation. Indomethacin $(10 \mu \mathrm{M})$ and atropine $(1 \mu \mathrm{M})$ partially blocked relaxation, whereas glibenclamide $(10 \mu \mathrm{M})$ did not change it. CNE significantly reduced mean systolic blood pressure in DOCA salt-induced hypertensive rats (from $185.3 \pm 4.7 \mathrm{mmHg}$ to $145.6 \pm 6.1 \mathrm{mmHg}$ ). The activity observed was supported by polyphenols, namely chlorogenic acid, vanillic acid, and ferulic acid identified in the extract. These findings reveal that the vasorelaxant and antihypertensive effects of CNE, through nitric oxide production in an endothelial concentration and dependent manner, are due to direct activation of the nitric oxide/guanylate cyclase pathway, stimulation of muscarinic receptors, and via the cyclooxygenase pathway [28].

\section{Duck beak (Bryophyllum pinnatum)}

Duck beak plant (Bryophyllum pinnatum), which is used as an antihypertensive, is shown in Figure 8 .

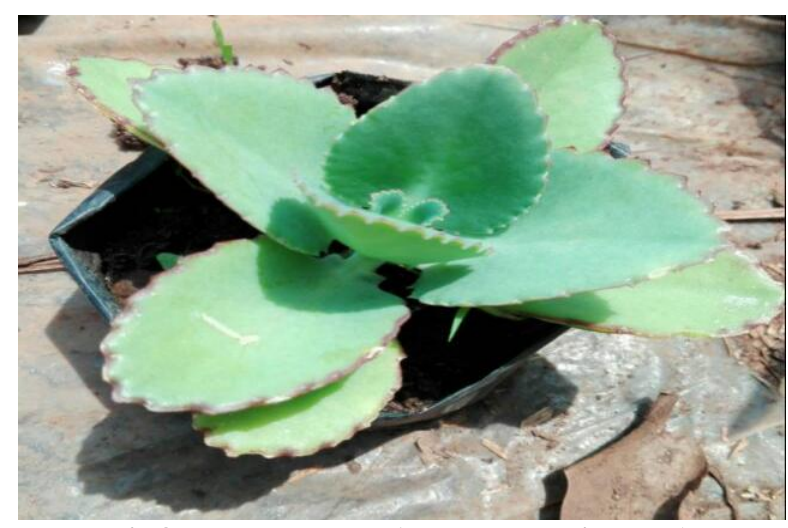

Fig-8: Duck beak plant (Bryophyllum pinnatum)

Bryophyllum pinnatum is a native and exotic plant widely used by traditional practitioners to treat various ailments such as kidney stones, hypertension, asthma, colds, abscesses, and bleeding disorders. The phytochemical, proximate, and mineral compositions of the leaves, stems, and roots of Bryophyllum pinnatum (Never die) were analyzed using the Association of Analytical Chemist (AOAC) standard methods and the Atomic Absorption Spectrophotometric (AAS) method. The qualitative phytochemical results showed that the plant samples contained alkaloids, tannins, saponins, terpenoids, glycosides, phenols, and flavonoids, which were not found in plant roots. The quantitative phytochemical results ranged from alkaloids $18.72 \pm$ $5.70 \%$, tannins $12.40 \pm 3.64 \%$, saponins $2.46 \pm 1.20$ $\%$, flavonoids $2.36 \pm 0.98 \%$, terpenoids $3.77 \pm 2.88 \%$ and phenol $10.48 \pm 8.59 \%$. The results of the proximate analysis ranged from $(3.18 \pm 3.13 \%)$ moisture, $(1.87 \pm 1.81 \%)$ ash, $(3.79 \pm 2.96 \%)$ protein, $(0.73 \pm 0.56 \%))$ lipids, $(3.10 \pm 1.84 \%)$ fiber, $(96.87 \pm$ $96.81 \%)$ dry matter and $(92.35 \pm 90.90 \%)$ nitrogenfree element (NFE). Mineral yields ranged from $40.88 \pm$ 28.65 ppm, $36.56 \pm 18.53$ ppm, $48.72 \pm 29.78$ ppm, $30.4 \pm 17.17 \mathrm{ppm}, 2.339 \pm 1.489 \mathrm{ppm}, 0.27 \pm 0,20$ ppm, $0.20 \pm 0.12$ ppm, $0.087 \pm 0.033$ ppm, $0.66 \pm 0.40$ ppm for $\mathrm{Ca}, \mathrm{Mg}, \mathrm{Na}, \mathrm{K}, \mathrm{Fe}, \mathrm{Mn}, \mathrm{Cu}, \mathrm{Zn}$, and $\mathrm{PO}_{4}$ respectively. The presence of phytochemicals, proximate, and mineral elements in plants can be part of the supporting factors that suggest plants' use for various therapeutic applications. It also indicates that the Bryophyllum pinnatum plant is a good source of human nutrition and should be included as a dietary supplement [12].

\section{New Chinese leaves (Artemisia campestris $\mathbf{L}$.)}

The new Chinese leaf plant (Artemisia campestris L.), used as an antihypertensive drug, is shown in Figure 9 below.

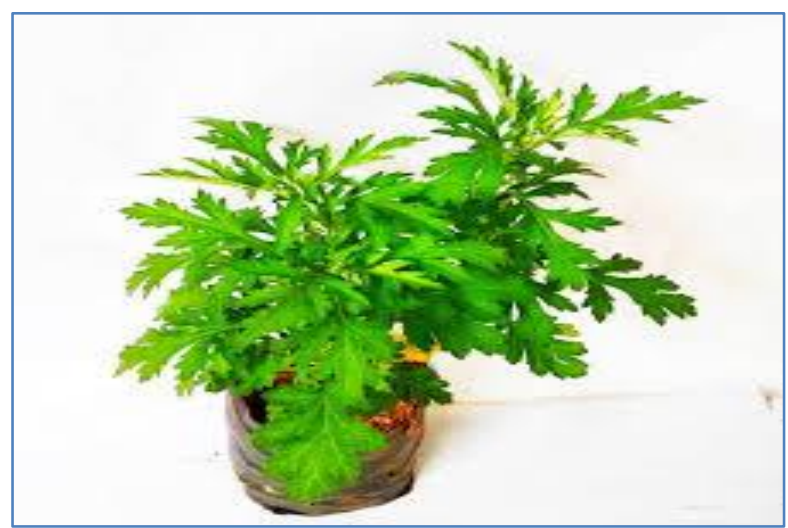

Fig-9: Chinese new leaf plant (Artemisia campestris L.)

Artemisia campestris L. (Asteraceae) is a perennial herb, commonly known as field worm word. This plant is widely distributed in Asia, North America, Europe, and North Africa. Various parts of this plant are anthelmintic, antidiabetic, antihypertensive, emmenagogue, antivenom, and treat digestive and skin problems. This plant contains rich phytochemicals and various pharmacological activities such as antioxidant, insecticidal, antibacterial, antimutagenic, antivenom, and antitumor effects. Based on clinical trials conducted on 14 adult smokers and volunteer non-smokers, diastolic pressure and heart rate decreased after 30-45 minutes in both groups after drinking A. campestris L leaf decoction at a dose of $20 \mathrm{mg} / \mathrm{mL}$ without affecting the average blood pressure of the last non-hypertensive group. The percentage of men with hypertension who had been previously diagnosed in the smoking group decreased from 50 to $33 \%$ after one hour of taking the boiled water extract. While this suggests an immediate 
response, these results indicate this plant extract's potential for treating hypertension.[13]

\section{Prickly acacia (Acacia nilotica L.)}

Thorny acacia (Acacia nilotica L.), which is efficacious for treating hypertension, is shown in Figure 10 below.

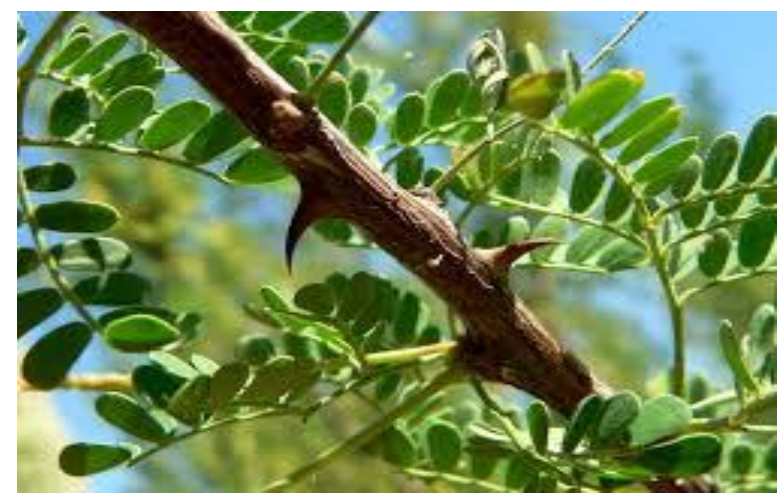

Fig-10: Plants of thorny acacia (Acacia nilotica L.)

Acacia nilotica (L.) is an important ornamental and medicinal plant in tropical and sub-tropical regions belonging to the genus Acacia's Fabaceae family. These herbs are the source of many active secondary metabolites, potential candidates for drug development with the greatest likelihood of success shortly. Tannins, flavonoids, alkaloids, fatty acids, and polysaccharides (gums) are the main classes of this plant's phytoconstituents. Pharmacological database reports have revealed significant anti-inflammatory, antioxidant, antidiarrheal, antihypertensive and antispasmodic, antibacterial, anthelmintic, antiplatelet, anticancer, and acetylcholinesterase (AChE) inhibitory activity [14].

\section{Jeringau (Acorus calamus L.)}

Jeringau plant (Acorus calamus L.), which is used as an antihypertensive drug, is shown in Figure 11 below.

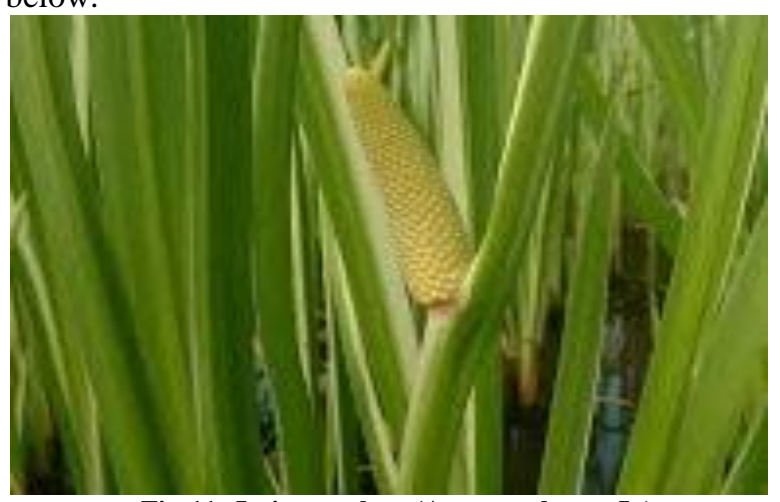

Fig-11: Jeringau plant (Acorus calamus L.)

Acorus calamus Linn. (Acoraceae) is a traditional Indian medicinal herb, which is practiced to treat various health ailments, including neurological, gastrointestinal, respiratory, metabolic, kidney, and liver disorders. To date, 145 constituents have been isolated from this herb and identified, including phenylpropanoids, sesquiterpenoids, and monoterpenes. Strong evidence shows the biopotential of various extracts and their active components in several metabolic and neurological disorders, such as anticonvulsant, antidepressant, antihypertensive, antiinflammatory, immunomodulatory, neuroprotective, cardioprotective, and antiobesity effects [15].

\section{Purple, golden gold (Ruellia)}

Purple, golden plants used as antihypertensive drugs are presented in Figure 12 below.

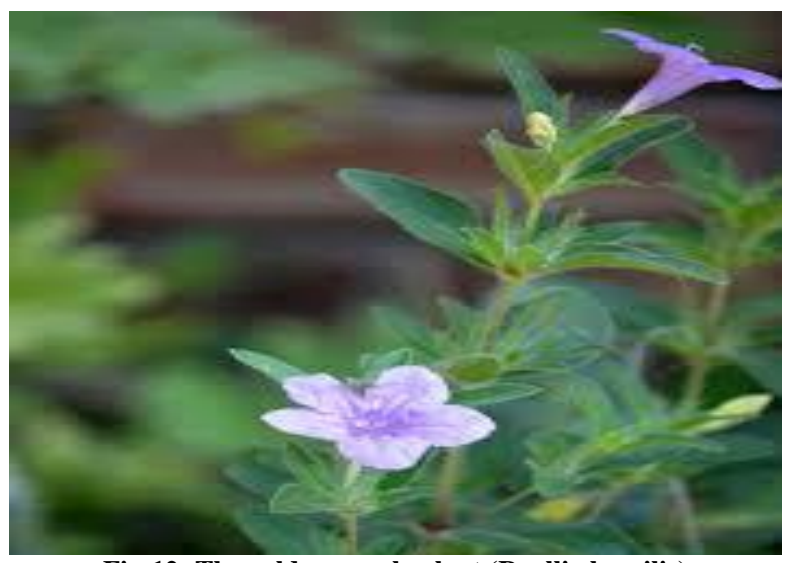

Fig-12: The golden purple plant (Ruellia humilis)

Ruellia is a genus of flowering plants called Ruellias or Wild Petunias, which belongs to the Acanthaceae family. It contains about 250 genera and 2500 species. Most of these are shrubs or twining vines; some are epiphytes. Only a few species are distributed in temperate climates. They are scattered in Indonesia and Malaysia, Africa, Brazil, Central America, and Pakistan. Some of them are used as medicinal plants. Many genus species have antinociceptive, antioxidant, analgesic, antispasmolytic, antiulcer, antidiabetic, and anti-inflammatory properties. Phytochemical constituents: glycosides, alkaloids, flavonoids, and triterpenoids are present. This genus is traditionally claimed to treat colds, asthma, hay fever, bronchitis, high blood pressure, eczema, and diabetes [16].

Two lignan glycosides were identified as 5,5'dimethoxylariciresinol-9-O- $\beta$-D-glucopyranoside (rupaside), and lyoniresinol-9'-O- $\beta$-D-glucopyranoside along with ethyl- $\alpha$-D-galactopyranoside, $\alpha$ - and $\beta$-Dglucose, and $\beta$-D-fructose have been isolated from Ruellia patula. Their structure is determined based on spectral evidence. Initial cardiovascular screening of butanol and water fraction suggests possible cardiotonic activity. However, additional studies will be needed to confirm this type of activity [29].

\section{Milk thistle (Silybum marianum)}

Milk thistle (Silybum marianum), which is used as an antihypertensive drug, is presented in Figure 13 below. 


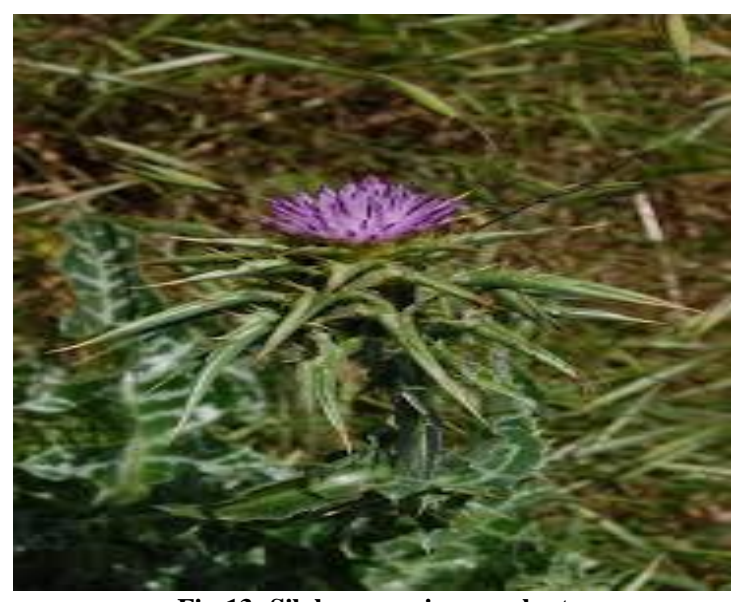

Fig-13: Silybum marianum plant

Silybum marianum (Milk thistle), a member of the Asteraceae family, is a tall plant with large, spiny white-veined green leaves and reddish-purple flowers sharp thorn tips. Certain phytoconstituents are revealed such as silybin $A$, silybin $B$, isosilybin $A$, isosilybin $B$, silychristin, silydianin, apigenin $7-\mathrm{O}-\beta-(2 "-\mathrm{O}-\alpha-$ rhamnosyl) galacturonide, kaempferol 3-O- $\alpha-$ rhamnoside-7- O- $\beta$-galacturonide, apigenin 7-O$\beta$ glucuronide, apigenin 7-O- $\beta$-glucoside, apigenin 7-O$\beta$-galactoside, kaempferol-3-O- $\alpha$-rhamnoside, kaempferol, taxifolin, and quercetin. This herb is used exclusively as an antidiabetic, hepatoprotective, hypocholesterolemic, antihypertensive, antiinflammatory, anticancer, and antioxidant. The plant seeds are also antispasmodic, neuroprotective, antiviral, immunomodulant, cardioprotective, antidote, and antibleeding. This herb also functions as a galactagogue and is used in the treatment of uterine disorders [17]

This study aimed to evaluate the efficacy of silymarin therapy in DOCA salt-induced hypertension in rats undergoing unilateral nephrectomy. Unilateral nephrectomy was performed on female Wistar rats (150-200 g). One week after unilateral nephrectomy, hypertension was induced by DOCA $(25 \mathrm{mg} / \mathrm{kg}$, once a week; s.c; for four weeks) dispersed in cottonseed oil. The effect of silymarin $(300 \mathrm{mg} / \mathrm{kg}$ and $500 \mathrm{mg} / \mathrm{kg}$, p.o. for four weeks) was evaluated in hypertensive rats induced by DOCA salt. Systolic blood pressure (BP) is measured once every week during the treatment schedule. After completing the treatment schedule, heart rate, arterial blood pressure, and vascular reactivity to various drugs were recorded. Rats from the individual group were sacrificed, their hearts were operated on, and antioxidant enzymes SOD, CAT, GSH, and TBARS were measured. Urine excretion was measured with a flash photometer. Silymarin $(300,500$ $\mathrm{mg} / \mathrm{kg} /$ day, p.o. $)$ significantly $(\mathrm{p}<0.05)$ decreased systolic blood pressure, heart rate, basal artery blood pressure, and pressor response to NA, Adr, PE, and 5HT in treated with DOCA salt compared with DOCA salt hypertensive mice. Silymarin significantly increased antioxidant enzymes SOD, CAT, GSH, urinary $\mathrm{Na}^{+}$excretion and decreased TBARS levels, and urinary $\mathrm{K}^{+}$excretion compared to the DOCA hypertensive group. Silymarin showed significant antihypertensive activity in the DOCA salt hypertension model [30].

\section{Parasitic benalu (Viscum articulatum Burm. f)}

Parasitic benalu (Viscum articulatum Burm. f), used as antihypertensives, is illustrated in Figure 14 below.

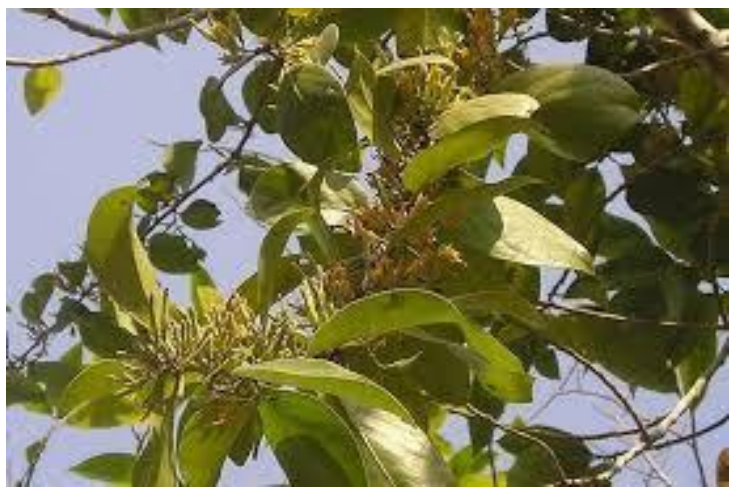

Fig-14: Parasitic benalu (Viscum articulatum Burm.f)

Viscum articulatum has been used traditionally in various parts of the world for the treatment of multiple diseases. Almost all aspects such as leaves, roots, stems, and bark have medicinal properties and are reported to be used in traditional medicine systems to treat various diseases. Modern scientific studies show this plant's efficacy against hypertension, ulcers, epilepsy, inflammation, wounds, nephrotoxicity, HIV, cancer, etc. The main bioactive phytochemicals include oleanolic acid, betulinic acid, eriodictyol, naringenin, bamyrin acetate, visartisides [18].

This study was designed to evaluate the antihypertensive activity of oleanolic acid isolated from Viscum articulatum Burm. (Loranthaceae) on glucocorticoid (dexamethasone)-induced hypertension in mice and propose a possible action mechanism for this effect. Male Wistar rats (300-350 g) received dexamethasone $(20 \mu \mathrm{g} / \mathrm{kg} /$ day s.c.) or saline (carrier) for 10 days. In a preventive study, mice received oleanolic acid (60 mg/kg i.p.) for five days, followed by dexamethasone or salt for ten days. During this period, the systolic blood pressure and body weight are evaluated alternately. At the end of the experiment, the thymus gland's weight was determined, plasma nitrate/nitrite concentration (nitric oxide metabolite), and cardiac lipid peroxidation value. Oleanolic acid (60 $\mathrm{mg} / \mathrm{kg}$ i.p.) significantly prevented increases in systolic blood pressure and cardiac lipid peroxidation levels after dexamethasone administration ( $p<0.01$ and $\mathrm{p}<$ 0.05 , respectively) without showing a significant effect on the induced changes-dexamethasone in body weight and thymus. Dexamethasone-induced reduction in plasma nitrate/nitrite concentrations was significantly prevented in the oleanolic acid-treated group $(\mathrm{p}<0.05)$. These findings suggest that oleanolic acid $(60 \mathrm{mg} / \mathrm{kg}$ i.p.) prevents dexamethasone-induced hypertension in 
mice, which may be attributed to the antioxidant and nitric oxide-releasing action.[31]

\section{The king's ulam (Cosmos caudatus)}

The king's ulam plant (Cosmos caudatus), which is used as an antihypertensive, is shown in Figure 15 below.

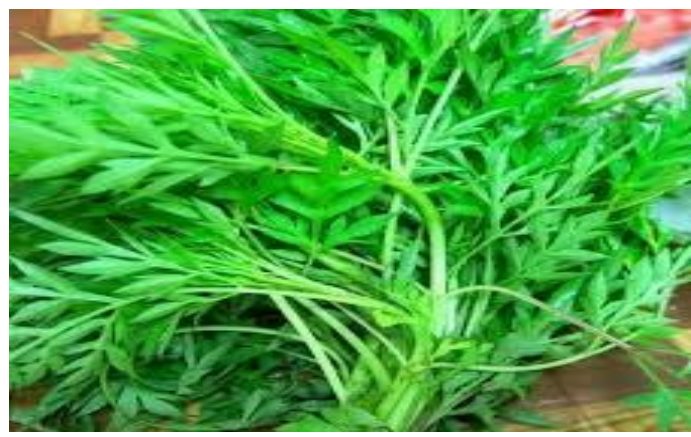

Fig-15: Plants of the king's ulam (Cosmos caudatus)

Cosmos caudatus or Ulam Raja in Malay originated from Latin America and was transferred to Europe, Africa, and tropical Asia. It has been recognized for many traditional practices worldwide, such as strengthening bones and improving blood circulation. This review aims to summarize and discuss the relationship between the phytochemical and pharmacological reports of C. caudatus and its traditional use via an ethnopharmacological approach. Cosmos caudatus is a traditional medicinal plant which is used widely for culinary and therapeutic purposes. Phytochemical studies show phenolic acid, flavonoids, tannins, lactone sesquiterpenes, carbohydrates, minerals, and vitamins in the leaves, while phenylpropanoids are in the roots. Pharmacological data have been collected for various activities for fresh leaves and their extracts, such as antihypertensive, antihyperlipidemic, antidiabetic, antimicrobial, antioxidant, and antiosteoporotic. This activity was carried out by in vitro and in vivo studies. Several constituents of $\mathrm{C}$. caudatus show many potential actions in areas such as neuroprotection, antidepressant, and gastrointestinal protection [19].

\section{Marrubium vulgare $L$.}

Marrubium vulgare L., which is used as an antihypertensive drug, is shown in Figure 16 below.

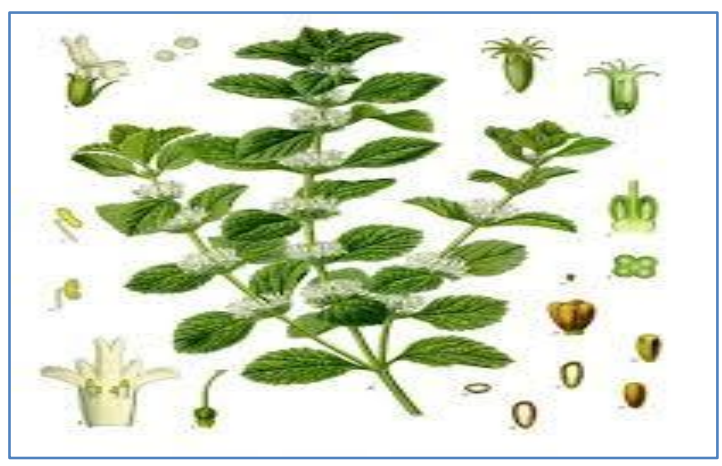

Fig-16: Marrubium vulgare L. plant
Marrubium vulgare L. (family: Lamiaceae), also known as white horehound, is widely used as a herbal remedy for chronic coughs and colds. It is used in various disorders related to the skin, liver, stomach, heart, and immune system. Phytochemical investigations on multiple parts of $M$. vulgare have reported the presence of flavonoids, steroids, terpenoids, tannins, saponins, and essential oils (0.05 $\%)$. The air portion contains marrubiin, along with ursolic acid and choline. Pharmacological activities include antinociceptive, antispasmodic, antihypertensive, antidiabetic, gastroprotective, antiinflammatory, antimicrobial, anticancer antioxidant, and antihepatotoxic activity have been reported. $\mathrm{M}$. vulgare has therapeutic potential in treating inflammatory conditions, liver disorders, pain, cardiovascular, gastric, and diabetic conditions. The airborne part of M. vulgare is a good source of labdane terpenes, especially marrubiin, which is present in high concentrations. However, further scientific studies are needed to explore the clinical efficacy and toxicity and explore the therapeutic effects of secondary metabolites such as diterpenes, phenylpropanoids, and phenylethanoid glycosides of M. vulgare [20].

The hypotensive effect of the aqueous extracts of Marrubium vulgare L. and Foeniculum vulgare L. was investigated in spontaneous hypertensive (SHR) mice and Wistar-Kyoto (WKY) normotensive mice. Oral administration of Marrubium extract or Foeniculum lowered the SHR systolic blood pressure but not WKY. In SHR, Foeniculum but not with Marrubium treatment increases water, sodium, and potassium excretion. Ex vivo and in vitro, Marrubium extract inhibited rat aortic contractile response to noradrenaline and $\mathrm{KCl}(100 \mathrm{mM})$. The inhibition was more significant in the aorta than SHR compared to WKY and was not affected by NO N-nitro-L-arginine synthase inhibitor. The vascular effect of Foeniculum extract is less pronounced than that of Marrubium and is blocked by N-nitro-L-arginine. These results suggest that Marrubium and Foeniculum extracts' hypotensive activity appears to be mediated via a different pathway: Foeniculum seems to act primarily as a diuretic and natriuretic while Marrubium exhibits vascular relaxant activity [32].

\section{Chickpea (Phaseolus vulgaris Linn.)}

Chickpea (Phaseolus vulgaris Linn), which is used as an antihypertensive, is presented in Figure 17 below. 


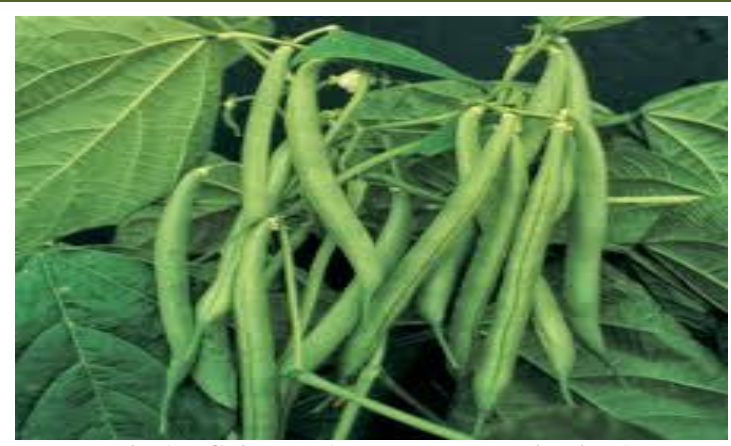

Fig-17: Chickpea (Phaseolus vulgaris Linn.)

Chickpeas (Phaseolus vulgaris L) have several bioactive components associated with health benefits, such as alkaloids, anthocyanins, carbohydrates, catechins, fiber, and flavonoids, phytic acid, quercetin, saponins, steroids, tannins, and terpenoids, and trypsin inhibitors. Therefore, Chickpeas have various biological activities, including analgesic, anti-inflammatory, antibacterial, antidiabetic, diuretic, antioxidant, hypocholesterolemic, and antiobesity [33].

This study aimed to evaluate the antihypertensive effect of the seed ethanol extract of Phaseolus vulgaris Linn. (EEPV) on high-salt dietinduced hypertension in male rats. Male Wistar rats (180-200 g) were fed high salt $(8 \% \mathrm{NaCl})$ and $1 \%$ brine for six weeks, then cannulated for the dose of Enalapril, an angiotensin-converting enzyme inhibitor $(0.5 \mathrm{mg} / \mathrm{kg}$, iv) in the standard group and EEPV (50 and $100 \mathrm{mg} / \mathrm{kg}$, iv) in the test arm and measured mean blood pressure, systolic blood pressure, diastolic blood pressure and heart rate with the help of Power Lab 6 Pro after 60 minutes of treatment. The increase in animal blood pressure was significantly $(\mathrm{P}<0.05)$ lowered by EEPV $(100 \mathrm{mg} / \mathrm{kg}$, iv). Enalapril, at a dose of $0.5 \mathrm{mg} / \mathrm{kg}$, iv showed a significant reduction $(\mathrm{P}<$ 0.05 ) in high blood pressure. Antihypertensive activity of Phaseolus vulgaris Linn seed ethanol extract possibly due to action on the renin-angiotensin system. EEPV's antihypertensive activity can also be explained by the presence of phytochemical constituents such as flavonoids and saponins in plants. The work shows that concurrent administration of high salt and EEPV leads to high salt-induced hypertension in mice. Overall, the results confirm and support the use of Phaseolus vulgaris Linn. as an antihypertensive drug [21].

\section{Nettle leaves (Urtica dioica $L$.)}

Nettle leaves (Urtica dioica L.), which are used as antihypertensive drugs, are shown in Figure 18 below.

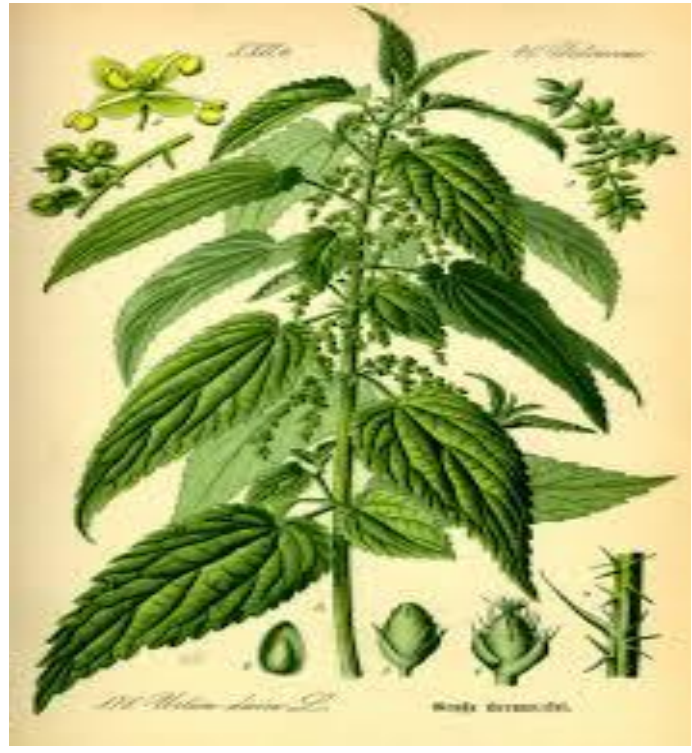

Fig-18: Leaves of Nettle (Urtica dioica L.)

Urtica dioica has traditionally been used in the treatment of cardiovascular disorders, especially hypertension. The purpose of this study was to determine the pharmacological basis of its use in hypertension. Crude methanol extract U. dioica (Ud.Cr) and its fractions (Ud.EtAc, Ud.nHex, Ud.Chl, and Ud.Aq) were tested in vivo on normotensive and hypertensive rats under anesthesia for their blood pressure-lowering effect. In-vitro experiments on the aorta of rats and rabbits were used to investigate the mechanism of vasorelaxation. The response is measured using a pressure and force transducer connected to the PowerLab Data Acquisition System. Ud.Cr and its antihypertensive fraction were more effective in hypertensive rats than normotensive with extraordinary potency shown by ethyl acetate fraction. The effect is the same as in the presence of atropine. In the isolated rat aortic ring, Ud.Cr and all its fractions exhibited a vasodilator effect dependent on 1-NAME-sensitive endothelium and inhibited $\mathrm{K}^{+}$-induced pre-contraction $(80 \mathrm{mM})$. In rabbit thoracic aortic ring isolated $\mathrm{Ud} . \mathrm{Cr}$ and its fraction induced relaxation with more significant $\mathrm{K}^{+}(80 \mathrm{mM})$ potential than phenylephrine $(1 \mu \mathrm{M})$ such as verapamil, showing the strongest Ud.EtAc fraction. Pre-incubation of the aortic ring with $\mathrm{Ud} . \mathrm{Cr}$ and its fraction showed $\mathrm{Ca}^{2+}$ channel blocking activity comparable to that of verapamil by shifting the $\mathrm{Ca}^{2+}$ concentration-response curve to the right. $\mathrm{Ud} . \mathrm{Cr}$ and its fraction also reduce intracellular $\mathrm{Ca}^{2+}$ release by suppressing PE peak formation in a $\mathrm{Ca}^{2+}$-free medium. When tested at basal stress, the crude extract and all fractions did not have a vasoconstrictor effect. These data indicate that crude methanol extract and its fraction have an antihypertensive effect. The identification of NO-mediated vasorelaxation effects and calcium channel blocking explains the antihypertensive potential of U. dioica and provides a potential pharmacological basis for drug use in hypertension management [22]. 


\section{Rhizoma Corydalis}

The Corydalis yanhusuo plant that plays a role in the treatment for antihypertensives is shown in Figure 19 below.

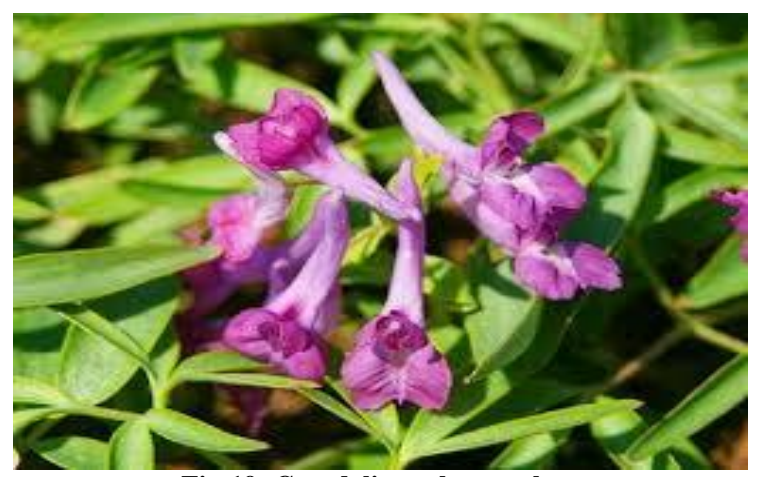

Fig-19: Corydalis yanhusuo plant

Rhizoma Corydalis (RC) is a dry tuber from Corydalis yanhusuo (Papaveraceae). Traditionally, RC was used to reduce pain, such as headaches, stomach aches, and epigastric pain. Modern medicine shows that it has analgesic, antiarrhythmic, and other effects. More than 100 chemical components have been isolated and identified from RC, of which alkaloids are the main active component of RC. Based on previous research, RC has antinociceptive, sedative, anti-epileptic, antidepressive and anti-anxiety, inhibitory effects of acetylcholinesterase, drug abstinence, anti-arrhythmia, anti-myocardial infarction, coronary artery dilatation, protection of cerebral reperfusion ischemia injury (I/R), antihypertensive, antigastrointestinal ulcers, liver protection, antimicrobial, anti-inflammatory, antiviral, and anticancer effects. RC is reported to be effective in treating various diseases. Recent pharmacological studies on RC have mainly focused on the nervous, circulatory, digestive, and endocrine systems and drug withdrawal. Although experimental data support the beneficial effects of this drug, its physiological activity remains a concern [23].

\section{Figs (Ficus carica L.)}

Tin or fig (Ficus carica L.), used as an antihypertensive, is shown in Figure 20 below.

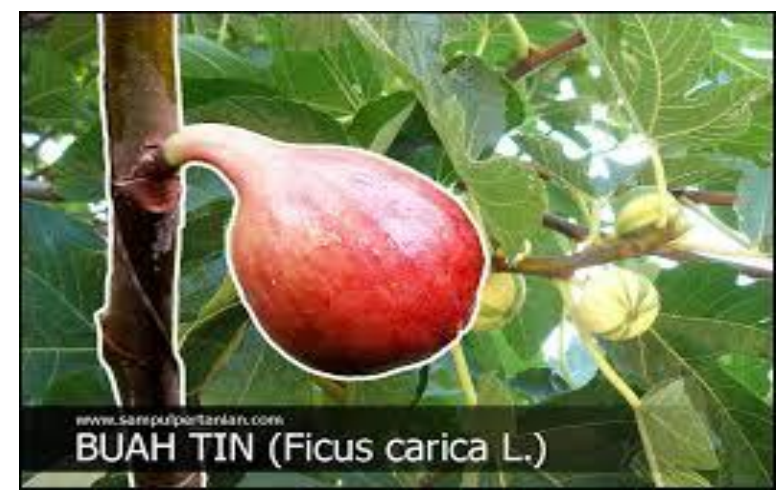

Fig-20: Figs (Ficus carica L.)
The fruit of Ficus carica L. (Moraceae) is said to have cardiovascular activity. It has been used empirically in traditional phytotherapy for the treatment of hypertension and various other cardiovascular diseases. This study investigated the antihypertensive activity and cardiovascular activity of the watermethanol extract of F. carica fruit in mice. Extracts in doses of 250, 500, and $1000 \mathrm{mg} / \mathrm{kg}$ (p.o.) were administered to normotensive Sprague Dawley mice, and their blood pressure was measured using noninvasive techniques. Hypertension was induced in mice by oral administration of glucose $10 \%$ for three weeks. The hypotensive effect of the extract $(1000 \mathrm{mg} / \mathrm{kg}$ p.o.) was studied in normotensive hypertensive rats and glucose treated. Langendorff's isolated heart technique was used to assess the crude extract's effect on contraction force and heart rate. The potency of antioxidants, TPC, TFC was also evaluated by the DPPH free radical scavenging activity, Folin-Ciocalteu reagent, and $\mathrm{AlCl}_{3}$ test. Furthermore, phenol compounds were analyzed using the HPLC-DAD technique. Doses of $1000 \mathrm{mg} / \mathrm{kg}$ significantly reduced blood pressure in hypertensive normotensive rats and glucose. Isolated cardiac studies showed that the extract produced adverse inotropic and chronotropic effects but failed to block the stimulating effects of adrenaline and $\mathrm{CaCl}_{2}$. HPLC studies on F. carica extract showed quercetin, gallic acid, caffeic acid, vanillic acid, syringic acid, coumaric acid, and chromotropic acid. This study showed that aqueous methanol extract of the fruit of $F$. carica exerted hypotensive and antihypertensive effects in glucose-induced hypertensive rats [24].

\section{Joho Rivet (Terminalia bellerica Roxb.)}

The joho rivet (Terminalia bellerica Roxb) used as an antihypertensive is presented in Figure 21 below.

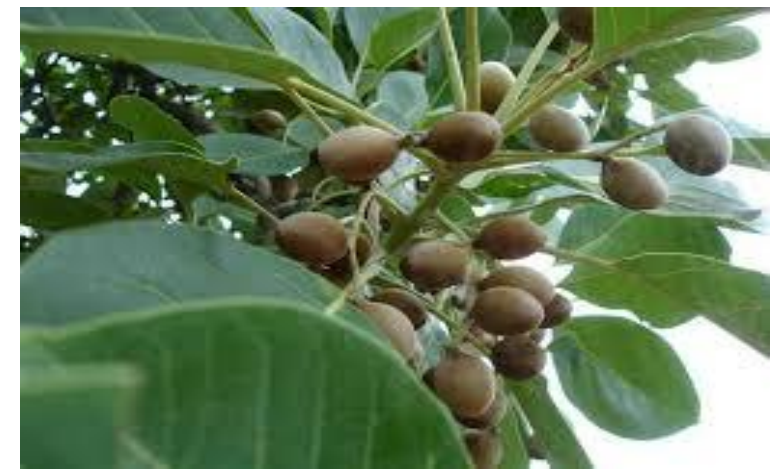

Fig-21: The plant of joho rivet (Terminalia bellerica Roxb.)

Terminalia bellerica Roxb (Combretaceae) is found widely throughout the Indian subcontinent, Sri Lanka, Southeast Asia, Bangladesh as a medicinal plant. These herbs and plant parts are used in traditional medicine systems. This plant contains glucosides, tannins, gallic acid, ethyl gallic, khebulinic acid, which functions as an antioxidant, antimicrobial, antidiarrheal, 
anticancer, antihypertensive, hepatoprotective \& antipyretic [25].

Terminalia bellerica has been used as a traditional medicine for various ailments, including hypertension. We aim to investigate possible mechanisms of the blood pressure-lowering effect (BP). Crude extract of Terminalia bellerica (Tb.Cr) fruit, which tested positive for flavonoids, sterols, and tannins, caused a dose-dependent drop in rat arterial blood pressure (10-100 mg/kg) under anesthesia. In the isolated guinea pig atrium, Tb.Cr inhibits the strength and speed of atrial contraction. In rabbit thoracic aorta, Tb.Cr relaxes phenylephrine $(\mathrm{PE}, 1 \mu \mathrm{M})$ and $\mathrm{K}^{+}(80$ $\mathrm{mM})$ induced contraction and suppresses PE $(1 \mu \mathrm{M})$ control peaks in $\mathrm{Ca}^{++}$-free medium, similar to that caused by verapamil. The vasodilator effect of Tb.Cr is endothelial independent because it is not opposed by $\mathrm{N} \omega$-nitro-L-arginine methyl ester in endothelial intact rat aortic preparations and occurs at similar concentrations in denuded endothelial tissue. These results suggest that Terminalia bellerica lowers blood pressure via a $\mathrm{Ca}^{++}$antagonist mechanism and provides an excellent mechanistic background for drug use in hypertension [34].

\section{CONCLUSION}

The search for this article found that 21 kinds of medicinal plants have antihypertensive properties. Plants that have antihypertensive properties contain the most flavonoid compounds. Therefore, these medicinal plants have the potential to develop into phytopharmaca as an antihypertensive drug.

\section{Conflict of Interests}

The authors declare that no conflict of interest is associated with this work.

\section{ACKNOWLEDGMENT}

The authors would like to thank the Chairman of STIFARM and the Dean of Faculty of Pharmacy, Andalas University.

\section{REFERENCES}

1. Landazuri P, Chamorro NL, Cortes BP. Medicinal plants used in the management of hypertension. $\mathrm{J}$ Anal Pharm Res. 2017;5(2):00134.

2. Sultana S, Muhammad Asif H. Medicinal plants combating against hypertension: A green antihypertensive approach. Pakistan Journal of Pharmaceutical Sciences. 2017 Nov 1;30(6):23119.

3. Mikail HG. Phytochemical screening, elemental analysis and acute toxicity of aqueous extract of Allium sativum L. bulbs in experimental rabbits. Journal of Medicinal Plants Research. 2010 Feb 18;4(4):322-6.

4. Nwokocha CR, Ozolua RI, Owu DU, Nwokocha MI, Ugwu AC. Antihypertensive properties of Allium sativum (garlic) on normotensive and two kidneys one hypertensive clip rats. Niger J Physiol Sci. 2011 Dec 26;26(2):213-8.

5. Fazal SS, Singla RK. Review on the pharmacognostical \& pharmacological characterization of Apium graveolens Linn. Indo Global Journal of Pharmaceutical Sciences. 2012;2(1):36-42.

6. Helaly AA, Baek JP, Mady E, Eldekashy MH, Craker L. Phytochemical analysis of some celery accessions. Journal of Medicinally Active Plants. 2015;4(1):1-7.

7. Rathee S, Rathee P, Rathee D, Rathee D, Kumar V. Phytochemical and pharmacological potential of kair (Capparis decidua). International Journal of Phytomedicine. 2010 Jan 1;2(1):10-7.

8. Singh V, Chauhan G, Krishan P, Shri R. Allium schoenoprasum L.: a review of phytochemistry, pharmacology and future directions. Natural product research. 2018 Sep 17;32(18):2202-16.

9. Jain S, Yadav PP, Gill V, Vasudeva N, Singla N. Terminalia arjuna a sacred medicinal plant: phytochemical and pharmacological profile. Phytochemistry Reviews. 2009 Jun 1;8(2):491502.

10. Zorofchian Moghadamtousi S, Hajrezaei M, Abdul Kadir H, Zandi K. Loranthus micranthus Linn.: biological activities and phytochemistry. Evidence-Based Complementary and Alternative Medicine. 2013;2013.

11. Lima EB, Sousa CN, Meneses LN, Ximenes NC, Júnior S, Vasconcelos GS, Lima NB, Patrocínio MC, Macedo D, Vasconcelos SM. Cocos nucifera (L.) (Arecaceae): A phytochemical and pharmacological review. Brazilian Journal of Medical and Biological Research. 2015 Nov;48(11):953-64.

12. Ogidi OI, Esie NG, Dike OG. Phytochemical, Proximate and Mineral compositions of Bryophyllum pinnatum (Never die) Medicinal plant. Journal of Pharmacognosy and Phytochemistry. 2019;8(1):629-35.

13. Dib I, Angenot L, Mihamou A, Ziyyat A, Tits M. Artemisia campestris L.: Ethnomedicinal, phytochemical and pharmacological review. Journal of Herbal Medicine. 2017 Mar 1;7:1-10.

14. Rather LJ, Mohammad F. Acacia nilotica (L.): a review of its traditional uses, phytochemistry, and pharmacology. Sustainable Chemistry and Pharmacy. 2015 Dec 1;2:12-30.

15. Sharma V, Sharma R, Gautam DS, Kuca K, Nepovimova E, Martins N. Role of Vacha (Acorus calamus Linn.) in Neurological and Metabolic Disorders: Evidence from Ethnopharmacology, Phytochemistry, Pharmacology and Clinical Study. Journal of Clinical Medicine. 2020 Apr;9(4):1176-1221.

16. Afzal K, Uzair M, Chaudhary BA, Ahmad A, Afzal S, Saadullah M. Genus Ruellia: Pharmacological and phytochemical importance in ethnopharmacology. Acta Poloniae 
Pharmaceutica-Drug Research. 2015 Sep 1;72(5):821.

17. Kumar T, Larokar YK, Iyer SK, Kumar A, Tripathi DK. Phytochemistry and pharmacological activities of Silybum marianum: a review. Apex. 2011;10:12.

18. Patel BP, Singh PK. Viscum articulatum Burm. f.: a review on its phytochemistry, pharmacology, and traditional uses. Journal of Pharmacy and Pharmacology. 2018 Feb;70(2):159-77.

19. Moshawih S, Cheema MS, Ahmad Z, Zakaria ZA, Hakim MN. A comprehensive review on Cosmos caudatus (Ulam Raja): pharmacology, ethnopharmacology, and phytochemistry. Int Res J Edu Sci. 2017;1(1):14-31.

20. Lodhi S, Vadnere GP, Sharma VK, Usman M. Marrubium vulgare L. A review on phytochemical and pharmacological aspects. Journal of Intercultural Ethnopharmacology. 2017 Jan $1 ; 6(4): 429$.

21. Jawaid T, Kamal M, Kumar S. Antihypertensive effect of the alcoholic extract of seeds of Phaseolus Vulgaris Linn. (Fabaceae) on high salt diet-induced hypertension in male rats. Int $\mathrm{J}$ Pharm Sci Res. 2017 Jul 1;8(7):3092-7.

22. Qayyum R, Qamar HM, Khan S, Salma U, Khan T, Shah AJ. Mechanisms underlying the antihypertensive properties of Urtica dioica. Journal of translational medicine. 2016 Dec;14(1):1-3.

23. Tian B, Tian M, Huang SM. Advances in phytochemical and modern pharmacological research of Rhizoma Corydalis. Pharmaceutical Biology. 2020 Jan 1;58(1):265-75.

24. Alamgeer, Iman S, Asif H, Saleem M. Evaluation of the antihypertensive potential of Ficus carica fruit. Pharmaceutical Biology. 2017 Jan 1;55(1):1047-53.

25. Deb A, Barua S, Das B. Pharmacological activities of Baheda (Terminalia bellerica): a review. Journal of pharmacognosy and phytochemistry. 2016 Jan 1;5(1):194.

26. Osadebe PO, Omeje EO, Nworu SC, Esimone CO, Uzor PF, David EK, Uzoma JU. Antidiabetic principles of Loranthus micranthus Linn. parasitic on Persea americana. Asian Pacific Journal of Tropical Medicine. 2010 Aug 1;3(8):619-23.

27. Iwalokun BA, Hodonu SA, Nwoke S, Ojo O, Agomo PU. Evaluation of the possible mechanisms of antihypertensive activity of Loranthus micranthus: an African mistletoe. Biochemistry research international. 2011 Jan 1;2011, Article ID 159439, 9 pages

28. Bankar GR, Nayak PG, Bansal P, Paul P, Pai KS, Singla RK, Bhat VG. Vasorelaxant and antihypertensive effect of Cocos nucifera Linn. endocarp on isolated rat thoracic aorta and DOCA salt-induced hypertensive rats. Journal of Ethnopharmacology. 2011 Mar 8;134(1):50-4.

29. Ahmad M, Akhtar MF, Miyase T, Ueno A, Rashid S, Usmanghani K. Studies on the medicinal herb Ruellia patula. International journal of pharmacognosy. 1993 Jan 1;31(2):121-9.

30. Jadhav GB, Upasani CD. Antihypertensive effect of Silymarin on DOCA salt-induced hypertension in unilateral nephrectomized rats. Oriental Pharmacy and Experimental Medicine. 2011 Aug 1;11(2):101-6.

31. Bachhav SS, Patil SD, Bhutada MS, Surana SJ. Oleanolic acid prevents glucocorticoid- induced hypertension in rats. Phytotherapy Research. 2011 Oct;25(10):1435-9.

32. Bardai SE, Lyoussi B, Wibo M, Morel N. Pharmacological evidence of hypotensive activity of Marrubium vulgare and Foeniculum vulgare in spontaneously hypertensive rat. Clinical and experimental hypertension. 2001 Jan 1;23(4):32943.

33. Ramadhani UP, Chandra B, Rivai H. Overview of phytochemistry and pharmacology of chickpeas (Phaseolus vulgaris). World Journal of Pharmacy and Pharmaceutical Sciences. 2020;9(9):442-61.

34. Khan AU, Gilani AH. Pharmacodynamic evaluation of Terminalia bellerica for its antihypertensive effect. Journal of food and drug analysis. 2008 May 1;16(3):6-14. 